\title{
ARE FORCED MIGRANTS MORE SKILLED? A THEORETICAL
}

\section{MODEL OF SELF-SELECTION IN FORCED MIGRATION}

Nermin Oruc

Center for Development Evaluation and Social Science Research, Sarajevo

nermin.oruc@gmail.com

lan Jackson

University of Wolverhampton

I.Jackson@wlv.ac.uk

Geoffrey Pugh

Staffordshire University

g.t.pugh@staffs.ac.uk

\begin{abstract}
This paper fills a gap in theories of forced migration. We present a new model, motivated by specific features of forced migration during a conflict which do not feature in existing migration models. We incorporate the relative deprivation hypothesis and a new "restoration" hypothesis in order to better explain forced migration as a two-stage process, which starts with conflict and, in some cases, forced displacement in the first stage and continues with emigration in the second stage. A particular feature of our model is that it predicts self-selection of highly skilled individuals into international migration as a result of conflict, since the "restoration" hypothesis assumes that
\end{abstract}


individuals with higher income before conflict are most under pressure to restore their previous income through emigration. The model used in this paper to analyse conflict-induced migration could also motivate further modelling to better match the characteristics of migration induced by natural disasters (which are expected to increase in the future as a result of climate change) as well as by large development projects.

KEYWORDS: FORCED MIGRATION; SELF-SELECTION; RELATIVE DEPRIVATION; THEORETICAL MODEL 


\section{Introduction}

The paper was motivated by two recent trends. The first was that, in its early stage, emigration from Syria and other war-torn countries was predominantly emigration by the rich and highly skilled, which was explained by the fact that "they emigrated because they could" (Mandic 2017). The second was the evidence of return from refugee camps in the Western Balkans, predominantly of Iranians who, as explained by experts working in these camps, paid the low price of reaching the Western Balkans and then returned to Iran because "they couldn't get used to life conditions in camps", since compared to refugees from countries such as Syria they were much better off before emigration. Whether forced displacements include a larger share of highly skilled individuals by driving them to move to a place where they will be less relatively deprived and where they can restore their previous level of well-being has already been empirically tested (e.g. Oruc 2009; Schon 2019). However, a clear theoretical explanation of the self-selection mechanism in the case of forced migration is still missing. This paper develops and tests a model that can contribute to a better understanding of such a mechanism.

In the analysis of the "brain drain", migration theory so far does not distinguish between different types of migration based on the predominant motives for migration. Neverthless, major migratory movements in history have been the result of forced displacement of people, based on race, religion or ethnicity. Once forced to leave a territory, these people are in a position to have particular incentives to migrate abroad. The events that cause the largest forced displacement of people from their properties are conflict, natural disasters and some development projects. Expected climate change is likely to increase the frequency of such events in the future. Consequently, this paper attempts to develop, within the framework of migration theory, a theoretical model that would help to assess the effect of such displacement on the emigration of highly skilled people and also the effect of such emigration on the stock of human capital in a 
country. In this way, we contribute both to the theory of the costs of wars and to migration theory. This paper does this by emphasizing additional negative effect of conflicts in the emigration of highly skilled people and analyzing migration theories of the "brain drain" in the specific context of forced migration.

There are at least two reasons that call for a separate analysis of the self-selection of forced emigrants. First, there is a risk factor introduced into the migration decision. Individuals with different personal characteristics may have different exposure ${ }^{1}$ and attitudes to risk, thus making different migration decisions. Secondly, individuals with different levels of education may have different levels of economic motivation for migration in the new context brought about by displacement during a conflict. For example, the opportunity costs of remaining in a country where the economy is negatively affected by a conflict should be higher for highly skilled individuals. All this motivates the development of a separate model of self-selection of forced migrants. The specific factors that may influence migration decisions by individuals from conflict areas may affect the skill composition of migrants, or the magnitude of "brain drain".

The extent to which forced migration will reduce the human capital stock in a country through "brain drain" will depend on the mechanism determining the skill composition of emigrants. The idea of a self-selection mechanism of migration was developed and explained by Stark and Taylor (1991). This mechanism explains the interaction between factors shaping the migration decisions and responses of individuals with different skills to these factors, which taken together affect the skill distribution of migrants. If the outcome of the interaction of these factors is that more emigrants are high rather than low skilled, then self-selection is recorded as positive;

\footnotetext{
${ }^{1}$ Individuals may have different exposure to risk and forced displacement, which may also be related to the skills of individuals. As reported by many witnesses of forced migration events, and according to the evidence collected in Gratz (2007) or Mandic (2017), individuals with tertiary education were more likely to be under attack during conflict. This outcome is due to their political activities to some extent, but also to the fact that a goal of conflict is to inflict more severe damages on the other side. In recent literature, such selection of highly skilled individuals into higher exposure to risk and forced displacement is termed "elitocide" (Gratz 2007).
} 
otherwise, negative. As explained previously, forced displacement involves a markedly different migration decision-making process and different factors affecting such a decision. Accordingly, this paper will attempt to develop a model to explain the self-selection mechanism in the context of forced migration. ${ }^{2}$ The analysis of forced displacement has been recognized in the terms of this paper as a gap in the current migration literature, which is generally focused on individual, regular migration. There has not previously been an attempt to develop a theoretical model that explains the process of migration conditioned by mass population displacement.

This paper also contributes to the literature concerned with the economic anlaysis of the costs of conflicts. Many conflicts in history, from ancient times to more recent wars in the Middle East, are characterized by forced mass displacement of people. Economic analyses of the costs of conflicts, as described in a review of these studies by Lindgren (2005), have mainly focused on the direct costs of conflicts, such as reduction of production capacities and infrastructure, deaths and injuries of the workforce as well as some indirect costs such as reduction in production, decrease in investments, capital flight, decrease in exports and imports and reduced income from tourism (Lindgren 2005: 5). Other indirect costs, such as depletion of human capital as a result of emigration of the highly skilled, are usually neglected in the estimates of the overall costs of a particular conflict, despite the fact that human capital is considered to be a key factor in economic growth.

The paper is structured as follows. The next section provides a critical overview of the literature and its relevance for the context of forced migration. In section three, the process of self-selection into migration because of change in the relative deprivation of displaced individuals is described with reference to qualitative evidence collected in Bosnia and Herzegovina. Section

\footnotetext{
2 The evidence presented in the paper is closely related to the "brain drain" as a result of displacement during a conflict (here the "ethnic cleansing" during the war in Bosnia and Herzegovina). However, we believe that the model is also applicable to other types of migration resulting from mass displacement, such as migration induced by natural disasters or development projects, since they share the same main characteristics.
} 
four presents the model of self-selection of forced migrants, which is developed by amending the model of voluntary migration according to the specific features of forced migration identified in section three. Finally, in section five, the paper provides conclusions.

\section{Literature review}

The importance of the emigration of highly skilled individuals from developing countries has been recognized since the early literature on the "brain drain". Several studies (Grubel and Scott 1966; Berry and Soligo 1969) discussed the welfare implications for a sending country of the emigration of highly skilled individuals, albeit at a rather theoretical level and with different predictions about the sign of this impact. This interest in the skill distribution among migrants in the literature was raised particularly after the recognition of the importance of human capital for economic growth in endogenous growth models (Lucas 1988).

Based on the work of Sjaastad (1962), neoclassical economics regards the migration process as an attempt by individuals to increase returns on their human capital. Migrants evaluate the expected benefits, such as discounted earnings and non-monetary returns, against the expected costs of migration, including both travel costs and non-monetary opportunity and psychological costs, and make the decision to migrate only if the total benefits from migration are larger than the total migration costs. The model predicts that younger and/or more skilled individuals migrate more, thus contributing to explaining the skill distribution of migrants.

The distribution of skills among the population of migrants has generally been investigated within the framework of self-selection models, ${ }^{3}$ which explain the relationship between the factors influencing emigration and the skill composition of migrants. Hence, if highly skilled migrants are more responsive to specific determinants of migration in a particular migration

\footnotetext{
${ }^{3}$ The following description of the self-selection model is based on the author's previous work (Oruc 2009).
} 
context, it is shown that migrants are positively self-selected. If the opposite is the case, and lowskilled migrants are more likely to migrate in response to specific determinants, then there is a negative self-selection of migrants.

In his seminal paper, Borjas (1987: 551) offered a model of self-selection of migrants applying the Roy (1951) model in the migration context. The Roy (1951) model is an alternative explanation of workers' labour market participation decisions. According to this model, individuals' choice of a sector in which to participate is not exogenous, but a result of an income maximization strategy, where they self-select into a sector that gives them the highest expected earnings. The sign of self-selection, or the distribution of skills among individuals, will depend on the variance in earnings between sectors. Borjas (1987) applied this model to migration in order to explain the skill distribution of migrants, treating countries as alternative sectors. In this twocountry model, where the countries can be denoted respectively as home and host country, potential migrants make comparisons between earnings in the home and the host country, and those who have higher earnings in a host country are those who actually migrate. Borjas assumes that costs are time-equivalent and constant across all individuals. The model suggests that an individual chooses to migrate whenever the difference in mean incomes, but also in returns on skills, between two countries is larger than the costs of migration.

The model has the ability to explain migration even if mean incomes between home and host countries are the same. In that case, individuals compare the variance in the returns on skills between two countries. The sign of self-selection of migrants thus crucially depends on the wage dispersion between the high- and low-skilled in the two countries. The more equal the wage dispersion, or income distribution, is in a home country, and/or the more unequal income distribution is in a host country, the more migrants will be positively self-selected with regards to their education level and vice versa. As richer countries have a generally more equal distribution of 
income, the model predicts that self-selection of migrants by their education level will generally have a negative sign. The model has been empirically tested by comparing the labour market performance of immigrants from Mexico to the US as a proxy for their unobservable skills, and evidence of negative self-selection of Mexican immigrants in the US was found (Borjas, 1987). For the purpose of the analysis of the self-selection model in forced migration, this model is important in terms of emphasizing the role of wage dispersion between the highly and the low-skilled. Evidence suggests that events causing forced migration, such as conflict or natural disaster, reduce this wage dispersion and inequality ${ }^{4}$ based on individual education levels. The model would then predict positive self-selection into migration after forced displacement due to a conflict or natural disaster.

The model has at least two shortcomings (Pedersen et al. 2004: 5). First, it does not consider any out-of-pocket migration costs. It may be expected that these costs, such as switching costs and/or "shoe leather" costs, are lower for the highly skilled, which may increase positive selectivity of migrants even when differences in income distribution between two countries are more favourable for low-skilled workers. Second, the model assumes the perfect ability of the potential migrant to observe mean incomes and returns on skills in two countries. Notwithstanding, in reality, the problem of imperfect information exists and is already acknowledged by migration literature as one of the factors explaining return migration. For the purpose of the analysis of self-selection of forced migrants, this model is a good starting point. However, it has to be augmented by factors other than the individual's wage in forced displacement settings, in order to explain the self-selection mechanism of this type of migration.

\footnotetext{
${ }^{4}$ One of the victims of the Haiti earthquake in January 2010, Fritz Mevs, said to Euronews that people there call this event "the most democratic event that ever happened in the history of Haiti ... The earthquake does not choose good neighbourhood, bad neighbourhood, rich neighbourhood." (Euronews: Rebuilding Haiti after the quake. 25.01.2010).
} 
The main contribution of this paper is that it recognizes a gap in the literature on forced migration and introduces a new model, which attempts to explain migration of individuals from countries affected by forced displacement, incorporating additional factors and two stages into the models of voluntary migration. Compared to the self-selection models of voluntary migration (Borjas 1987), where migration is a one-stage process, which is expected to bring an increase in the expected wage for the migrant, in the model proposed in this paper the migration is modelled in two stages.

Migrants in the case of forced displacement are assumed not to have an economic incentive to migrate before the forced displacement occurs. As the migration literature (Van Hear 1998; Chiswick 2000) generally accepts that economic factors of migration in the case of conflict or natural disaster do not disappear, although their influence on migration decisions may be reduced, the model proposed in this paper accounts for these factors and their change during such events. Once a conflict has occurred, the expected wage of potential migrants in a home country is changed. This is the first stage of the migration process. In the second stage, individuals compare their expected wage in the case of no conflict, their expected wage once it has occurred and their expected wage if they migrate. The larger the difference in expected wages between situations with and without a conflict, the stronger the incentive is for individuals to migrate. ${ }^{5}$ The selfselection mechanism in this context is the fact that the difference between expected wages in situations with and without a conflict is larger for individuals with higher observable skills. Once a conflict occurs, individuals from affected areas are very often forced to move to other areas. They suffer significant welfare losses. Others, from non-affected areas or who were not forced to move

\footnotetext{
${ }^{5}$ The hypothesis that predicts increased propensity to migrate by individuals more affected by forced displacement is called the "restoration hypothesis" and is explained in detail in Oruc (2009).
} 
to other areas, ${ }^{6}$ are also affected by decrease in economic activity in the country. The more skilled individuals are, whether displaced or non-displaced, the more significant the income losses may become. Besides absolute income, their relative position compared to a reference group is also worsened. It might be expected that the highly skilled have stronger incentives to leave refugee camps and restore their pre-conflict level of income and welfare as well as their relative position in a community.

Stark and Taylor (1991) argue that, besides absolute income considerations, the relative position of an individual within her community also determines their migration decision. Stark and Taylor's relative deprivation model is chosen as a framework in which the model of migration as a result of forced displacement will be developed (to be presented in the following section). This model is appropriate as it accounts for community characteristics and individuals' perceptions of their position in such a setting, as well as the fact that individuals compare their well-being not only to the well-being of others, but also to their own at a previous point in time.

The relative deprivation hypothesis was originally developed by Stouffer et al. (1949) in order to explain a series of unexpected relationships found in an analysis of the satisfaction of US soldiers. They found that African American soldiers stationed in the Southern USA were more satisfied than African American soldiers stationed in the Northern USA. The authors' explanation was expressed through the relative deprivation hypothesis. According to this hypothesis, individuals react to objective circumstances on the basis of their subjective comparisons. Thus, African Americans stationed in the South, who compared their position to that of other African Americans there, which was generally worse than in the North, may have been more satisfied with their position than those who compared their situation with the situation of other African Americans in the North. This means that individuals' valuations of their income will depend on the

\footnotetext{
${ }^{6}$ For example, the ones who in the case of ethnic cleansing lived in areas controlled by their ethnic group, and so were not evicted.
} 
income distribution in the reference group and their position within that group. So, the more the individuals in the reference group who have a larger income than an individual $i$, the more individual $i$ will be relatively deprived. An important contribution to the understanding and application of the idea of relative deprivation in the context of forced migration is provided by Runciman (1966: 10). He explained the relative deprivation of an individual as a situation where four conditions are met: 1 ) an individual does not have $X ; 2$ ) she sees others, including herself at a previous point in time, as having $X ; 3$ ) she wants $X$; and 4) obtaining $X$ is seen as feasible. The feeling of deprivation is explained through 1) and 3), where we can see that deprivation is the individual's disutility of not having $X$. The relativity of the concept arises from 2) and 4), as individuals' levels of deprivation depend on the income of a reference group to which the individual compares her income. Hence, an individual's level of deprivation will be a function of the proportion of individuals in a reference group who have income above the individual's income and the mean income of the group. When applied to migration, the relative deprivation hypothesis states that individuals evaluate migration decisions not only on the basis of absolute, but also of relative income differences within a community. Individuals compare their income with the typical income of a reference group and feel deprived by not having more than they have. This hypothesis predicts the migration of more relatively deprived individuals, as well as migration from more to less unequal societies.

In the context of forced migration, the second part of condition 2) stating that individuals also compare their current to their previous position becomes particularly relevant. This detail of Runciman's description of relative deprivation was mostly neglected in the previous literature on voluntary migration based on the relative deprivation hypothesis. Condition 2) states that individuals not only compare their position relative to a reference group, but also relative to their previous position. This outcome means that decrease in an individual's absolute income, and 
relative deprivation as a consequence of an adverse event such as a conflict or natural disaster, may increase a person's relative deprivation through them not having that income any more. This, another type of deprivation of an individual, relative to their previous income level, is a function of the change in absolute and relative income of an individual as a consequence of such an adverse event. It may be expected that the more severely affected by a conflict an individual is, the more relatively deprived and thus more prone to restore her previous well-being she will be. Consequently, the migration decision of individuals during a conflict is not only affected by their deprivation relative to a reference group, but also relative to their previous position.

As identified above, the relative deprivation theory is helpful in the context of this paper, as it allows us to consider not only the current absolute income and relative deprivation levels in modelling the migration decisions of forced migrants, but also the role of change in both absolute income and relative deprivation caused by a conflict. It is expected that this change in absolute income and relative deprivation acts as a self-selection mechanism. The higher the pre-conflict income of an individual, the more she is affected by a conflict in terms of her relative position during conflict compared to the pre-conflict period, hence the more likely she is to migrate. As income is positively correlated with education, it may be expected that a conflict increases "brain drain" from areas affected. However, this assumption needs to be tested empirically.

So far, there have been several attempts to develop specific models for forced migration (for example, Kirchhoff and Ibanez 2001 or Schaeffer 2005). The main characteristic of these models was that they introduced a factor of risk into the model developed for voluntary migration, without attempting to incorporate all the characteristics of the process of forced migration. Also, there has been a number of empirical studies on the determinants of forced displacement, both at the micro (Ibanez and Velez 2003; Czaika and Kis-Katos 2007) and the macro level (Davenport et al. 2003; Melander \& Oberg 2004; Moore \& Shellman 2006), but without accounting for the 
education level of migrants and, consequently, without evidence on the self-selection mechanism in the context of forced migration. Therefore, this paper can be considered as a first attempt to develop a theoretical model that should be well suited to the explanation of the phenomenon of self-selection in forced migration.

\section{Analysis of forced migration patterns during a conflict}

As explained previously, an event such as a conflict or natural disaster reduces economic opportunities for all individuals and introduces indirect threats. For these reasons, some individuals, although not forcibly evicted from their homes, decide to migrate abroad. The entire process of displacement in Bosnia and Herzegovina during the war, including both forced displacement and subsequent migration by the evicted and non-evicted, is described in more detail in Oruc 2015 and summarised in Figure 1 below. 
Figure 1. The pattern of displacement during a conflict

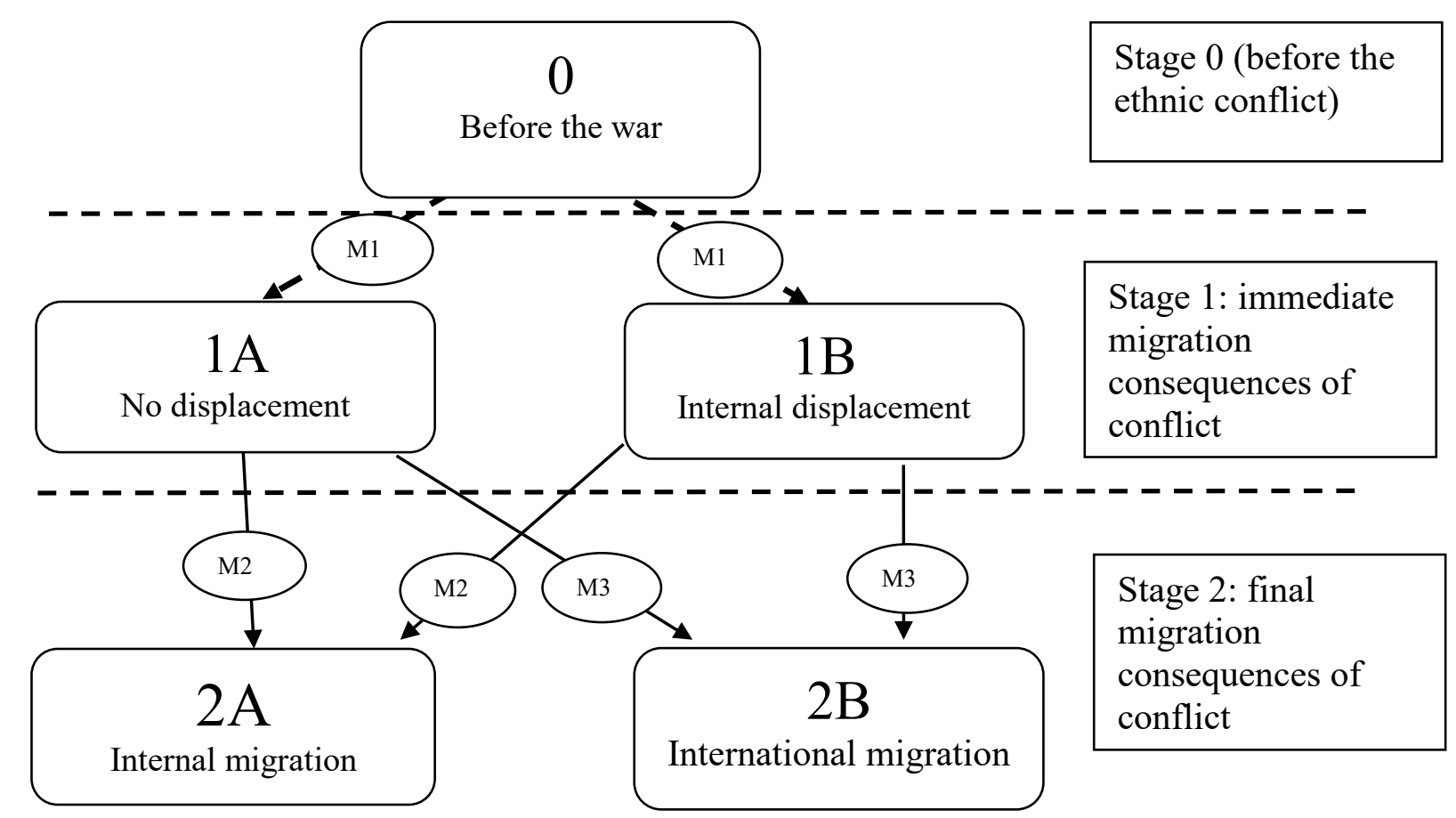

Source: Authors

Figure 1 describes three stages of conflict-related migration and the associated decisions of individuals, divided by dashed lines. The first level in the figure is Stage 0, which is the situation before war and displacement and sets the level of well-being with which individuals compare their well-being in the subsequent stages. As a "displacement event" occurs (in this case conflict, but it could also be a natural disaster or a development project) people move from 0 to 1 (the move presented by two dashed arrows denoted by M1 from Stage 0 to one of the two stages at the second level of Figure 1). The two types of status in which individuals may find themselves are distinguished as: one in which no displacement occurs (we denote this as type 1A status); or one in which they are displaced, initially internally (i.e. within their own country) (type 1B status). The individuals in Group 1A are not forced to move, but their well-being is affected by the conflict and consequent reduction in economic activity, employment and access to goods. Conversely, those in Group 1B experience displacement effects (e.g. having to leave their homes and the associated 
property loss) compounding the conflict effects experienced by Group 1A. The corresponding changes in individuals' well-being (moving from stage 0 to stage 1 ) are considered to be exogenously determined by the conflict. After these changes in well-being experienced by both individuals not displaced (Group 1A) and displaced individuals (Group 1B), both groups are faced with a decision about whether (i) to stay in the pre-war location (Group 1A) or the new location to which they were displaced (Group 1B), (ii) to migrate elsewhere within the country (i.e. from either $1 \mathrm{~A}$ or $1 \mathrm{~B}$ to Group $2 \mathrm{~A}$ - shown by arrows $\mathrm{M} 2$ ) or (iii) to migrate abroad (i.e. from either $1 \mathrm{~A}$ or $1 \mathrm{~B}$ to Group $2 \mathrm{~B}$ - shown by arrows $\mathrm{M} 3$ ). These migration decisions and corresponding changes in well-being are considered to be endogenously determined. So, Figure 1 presents the idea of a two-stage process of forced migration, where a reduction of well-being due to a conflict and displacement is the first stage, and migration driven by a consequent change in well-being is the second stage of migration. Such an understanding of forced migration is the main contribution of the theoretical model developed below, which amends previously developed models of voluntary migration by introducing a two-stage decision process.

The distinction between the two types of situations in which individuals find themselves is important for the correct identification of the extent to which the well-being of individuals with different characteristics is changed. This is important for measuring the size of the relative deprivation of individuals when they compare their position at the occurrence of conflict and before their migration decision (stage 1) with their pre-conflict position (stage 0). Their well-being is changed both in terms of absolute income and relative position within a reference group. According to the neoclassical economics theory of migration, large-scale migration from countries affected by a conflict is expected, because the absolute income of the vast majority of individuals is negatively affected by the conflict, so the pre-war utility of migration may change from being lower to becoming higher than the utility of staying. Also, the individuals who were forcibly 
evicted are expected to be more likely to migrate, as they suffered more significant losses in terms of their absolute income, and the gain from migration by these individuals, or their expected wage differential, is higher than by those who were not forcibly displaced. In addition to this, the relative deprivation hypothesis states that the migration decision will depend not only on the change in absolute income, but also on the change in individuals' position relative to a reference group. As a large proportion of individuals are affected, either by forced displacement and/or by reduced economic opportunities, the relative deprivation of each individual relative to the reference group will not necessarily increase for all individuals. Therefore, the relative deprivation hypothesis does not predict an increased overall number of migrants, but instead predicts positive self-selection of migrants according to their skill levels and corresponding previous levels of wellbeing. Furthermore, it suggests that we can observe migration by both those who were and those who were not forcibly displaced.

Based on the previous description, specific features of forced migration during a conflict can be identified. These specific features are now used as a platform to develop a formal model of forced migration as a result of conflict. Accordingly, the model of forced migration during a conflict, which is developed in the next section, should incorporate these features: the two-stage process and the influence of both absolute change in income and relative deprivation. In addition, the formal model also addresses risk (threat to life).

As defined previously, this paper aims to analyse factors affecting the migration of highly skilled individuals as a result of forced displacement, so it is of particular interest to understand how a forced displacement affects the skill composition of migrants. If it is assumed that highlyskilled people had a higher income and were less relatively deprived (or, in other words, they had higher levels of relative advantage) before the event causing displacement, then it could be expected that they suffer greater losses than low-skilled individuals in terms not only of absolute 
income but also of their relative advantage. Also, their relative deprivation compared to the position before the event causing displacement increases (more) compared to the relative deprivation of the low-skilled individuals. If highly skilled individuals have incurred greater welfare losses as a result of displacement, they may be more prone to emigrate in order to restore those losses. This may then act as a self-selection mechanism in forced migration. According to the neoclassical models of migration, we should observe an increased number of individuals migrating from areas affected by a conflict, but cannot predict their skill composition. Conversely, according to the relative deprivation hypothesis, in the case of conflict-induced forced migration, a positive self-selection of individuals according to their skill levels should be observed. This means that conflict increases total emigration from a country by decreasing the absolute income of individuals (neoclassical models), but also increases the emigration rates of highly skilled individuals by decreasing their relative position within the society (relative deprivation hypothesis). Empirically, this would mean that the observed outcome, on average, is a larger proportion of highly skilled forced migrants outside the country as a result of conflict compared to voluntary migration. The empirical testing of this hypothesis can be made possible at an international level by using data on the skill composition of migrants, such as the data collected by Docquier and Marfouk (2006), or at a within-country level as done by Oruc (2009).

\section{The model}

The pattern of displacement presented in Figure 1 reveals that forced migration during a conflict, compared to voluntary migration, involves large-scale forced displacement of individuals, and that such an event changes both the absolute and the relative income and well-being of individuals. Individuals compare their pre- and post-conflict well-being, and their migration decisions are affected by the differences between their well-being in the two periods. These 
specific features of forced migration are not taken into consideration in the models of voluntary migration. As a consequence, a specific model for forced migration needs to be developed.

The following model of forced migration is based on Stark and Taylor (1991), in which a relative deprivation hypothesis is presented. Some of the steps of mathematical transformation were applied in the same way as in their model, in order to make these two models comparable. This procedure enables us to point out the main features of the new model and to show how it differs from voluntary migration models, such as the one presented in Stark and Taylor (1991). One of the key differences is that the model proposed in this paper is presented as a two-stage process. In the first stage, individuals' utility is exogenously affected by conflict (move from 0 to $1 \mathrm{~A}$ in Figure 1) or by both conflict and displacement (move from 0 to $1 \mathrm{~B}$ in Figure 1). In the second stage, individuals' utility is changed as a result of their endogenous migration decision (change from $1 \mathrm{~A}$ or $1 \mathrm{~B}$ to either $2 \mathrm{~A}$ or $2 \mathrm{~B}$ in Figure 1 ), where the migration decision of an individual is based on the comparison of her or his income and relative deprivation before (Stage 1) and after (Stage 2) migration, but conditional on these values before a conflict (Stage 0). The most important feature of the proposed model is a new hypothesis, based on Runciman's original explanation of relative deprivation, that refers to an individual's comparison of their current level of well-being with their level of well-being at a previous point in time, as well as a "restoration hypothesis", which is incorporated into the model.

The relative deprivation hypothesis, introduced in the migration context by Stark and Taylor (1991), states that individuals evaluate migration decisions not only on the basis of absolute, but also of relative income differences within a community. Individuals evaluate their position relative to the community and feel deprived of having commodities that individuals richer than them have. The further below the average community income the individual earns, the more prone that individual is to migrate (in order to improve their income position relative to the community). 
Under the assumption of a continuous income distribution, where each income unit can be represented by a range $(x, x+\Delta x)$ and where $\Delta x \rightarrow 0$, the relative deprivation function of an individual is presented by the following equation:

$$
R D_{i}=\int_{y_{i}}^{y_{h}} g[1-F(x)] d x
$$

Here, $R D_{i}$ denotes the relative deprivation of individual $i, y_{i}$ the income of individual $i$ (which we assume to give the level of well-being of an individual), $y_{h}$ the highest income in the reference group, $x$ represents an income unit (or Runciman's X), $F(x)$ the cumulative distribution of income in a reference group (Lorenz curve) and $1-F(x)$ the percentage of individuals whose income is higher than $x$. Equation (1) represents the area below the Lorenz curve between the individual's position and the position of the richest person in a community. This shows that the relative deprivation of an individual can be reduced by either increase in her income or by decrease in the income of the richer individuals. Stark and Yitzhaki (1988) provided a proof that the right-hand side of Equation (1) can be decomposed into the product of (i) the proportion of individuals whose income is higher than that of an individual $i$ and (ii) their mean excess income. Hence, this hypothesis suggests that, given absolute income levels and expected gains from migration, individuals who feel more relatively deprived compared to their well-being before the conflict are more likely to migrate. Moreover, the direction of migration flows should be from societies with higher to societies with lower income inequality. In addition to this, if we extend this idea onto the other part of Runciman's original explanation of the relative deprivation hypothesis 
described above, ${ }^{7}$ related to individuals' comparisons of their present well-being with their wellbeing in some previous period, then we should expect that those who were affected by forced displacement feel more severely deprived in terms of their current to pre-conflict position and thus are more likely to migrate.

This insight suggests introducing a new hypothesis into migration models. The "restoration hypothesis" is based on the observation that conflict and displacement affect individuals' wellbeing. They work as a shock to the economy of a country and result in decrease in economic activity, increase in prices, fall of real wages etc., which cause decrease in the value of the income element of an individual's utility function. Consequently, conflicts generally increase the level of relative deprivation of individuals compared to their position in the pre-conflict period, so they are therefore expected to increase overall migration from areas affected by conflict. The more wellbeing is worsened, the more likely individuals should be to migrate abroad in order to restore their pre-conflict well-being. ${ }^{8}$ As presented in Figure 1 , some individuals may experience additional decrease of both absolute income and relative position within a community (which affects their relative deprivation) through the losses of site-specific capital due to displacement (change from 0 to $1 \mathrm{~B})$. Based on the restoration hypothesis, it may be expected that all individuals experience certain welfare losses due to conflict and that those who experience more significant losses, both absolute and relative, are more prone to migrate in order to restore their pre-event level of utility. It should be also expected that individuals who were richer before the war will suffer larger absolute losses due to the war. Moreover, regarding relative deprivation, it could be expected that

\footnotetext{
${ }^{7}$ As mentioned already a few times, the part of Runciman's original explanation of the relative deprivation hypothesis stating that individuals compare their well-being not only relative to their community but also to their own at a previous point in time, was generally neglected in migration literature, because of the characteristics of voluntary migration. Once mass forced displacement is described as a two-stage process, in which the second stage decision is conditional on the first stage changes in income and relative deprivation, this part of the Runciman's explanation becomes particularly relevant.

${ }^{8}$ The term "restore" used here does not mean that the model assumes that individuals will be as well off after migration as before ethnic cleansing, but it assumes that individuals are expected to be better off after migration than they would be had they decided not to migrate.
} 
richer individuals are worse off in terms of the increase in their relative deprivation (or decrease in their relative advantage), while poorer individuals may become better off in terms of relative deprivation, as a result of the negative impact of conflict on overall welfare. Thus, the "restoration hypothesis" predicts that individuals who migrate as a result of their absolute income differences and relative deprivation will be positively selected in terms of their income and, accordingly, in terms of their level of education. This is of particular importance for the analysis of the impact of forced migration on the magnitude of "brain drain" from the affected country.

Following Stark and Taylor's (1991) hypothetical example, it is assumed initially that half of the population in a village have an income of 150 income units and the other half 100 income units, while income in a town is 200 units. If, due to a shock, the income of the first group falls from 150 to 100 and of the second group from 100 to 80 , a decrease in migration by individuals from the group with an income of 80 may be observed. Although the second group experiences an absolute decrease in income, their relative position actually improves due to the decrease in the average income of the reference group. However, the first group, with higher relative income, experiences decrease in both absolute income and relative position. Therefore, the first group would now be more inclined to migrate to a town in order to restore both their absolute income and their relative position. In the case of refugees, it may be expected that individuals with higher pre-war income may be less able to adapt to new conditions brought about by a conflict than individuals with lower income, thus having an additional motive for migration. These insights will now be incorporated into the model of forced migration.

In any model of migration, assuming that individuals are rational economic agents, we should expect that they will decide to migrate only if:

$$
U_{i 1}>U_{i 0}
$$


where $U_{i 1}$ denotes the utility of an individual $i$ after migration and $U_{i 0}$ their utility with no migration. According to the Neoclassical economic theory, utility is primarily based on wage, thus wage differentials between two countries are the main driving force of migration. But, as explained above, an individual's utility is based not only on absolute income but also on relative deprivation and its change between two periods, as well as on risk (threat to life). Consequently, for the explanation of displacement during a conflict, we need to incorporate both the relative deprivation hypothesis developed by Stark and Taylor (1991) and the restoration hypothesis proposed here, in order to develop a model to generate satisfactory predictions about this type of migration process.

So, the utility of an individual is then:

$$
\begin{aligned}
& U_{i j}=U\left(Y_{i j}, R D_{i j}, X_{i j}\right) \\
& \delta U_{i j} / \delta Y_{i j}>0, \\
& \delta U_{i j} / \delta R D_{i j}<0 \text { and } \\
& \delta U_{i j} / \delta X_{i j}>0
\end{aligned}
$$

where: $U$ denotes utility; $U()$ denotes the function on the right-hand side of Equation 3 that determines the individual's utility; $Y$ denotes absolute income; $R D$ relative deprivation; $X$ the level of risk (ranging between $1=$ no risk and $0=$ maximum risk, hence, the inverse of risk or a measure of security); subscript $i$ the individual observation; and subscript $j$ the stage in the process described in Figure $1, j=0,1,2$, where 0 is the pre-displacement situation (Stage 0 in Figure 1 ), 1 is the situation during the war and before displacement, where we have decrease in utility due to displacement and/or conflict (Stage 1 in Figure 1), and 2 is the case of migration (Stage 2 in Figure 
1). The first part of Equation (3) shows that the individual's utility is a function of their income, relative deprivation, and the level of risk. The second part of the equation explains that their utility is an increasing function of income and security and a decreasing function of relative deprivation.

At this point, it is assumed that $U_{i 0}>U_{i 2}>U_{i 1}$, where $U_{i 0}$ denotes an individual's utility before occurrence of conflict, $U_{i 1}$ their new utility after the start of conflict, and $U_{i 2}$ utility after migration. This means that individuals in the country when a conflict or a natural disaster happened were in the country because their utility from staying was higher than their utility from migrating, so they were not potential migrants. This assumption excludes the possibility of "bogus refugees". ${ }^{9}$ Nevertheless, as displacement occurs, the utility of an individual may change, which induces migration of individuals that would otherwise not migrate.

We now move to modelling the change in utility as a result of the first stage of the process described in Figure 1, i.e. displacement and/or conflict. At this point, we drop subscript $i$ to avoid clutter, and to emphasize the subscripts denoting the differentiation of stages, i.e. 0,1 and 2 in Figure 1. However, the model still refers to individuals. The net utility loss from the first stage of the conflict (affecting all individuals in a country) and of displacement (affecting some individuals) is then (where $\Delta$ denotes change):

$$
\begin{aligned}
& \Delta U_{1}=U_{1}-U_{0}=U_{1}\left(Y_{1}, R D_{1}, X_{1}\right)-U_{0}\left(Y_{0}, R D_{0}, X_{0}\right) \\
& U_{1}<U_{0} \\
& Y_{1}<Y_{0} \text {, and } \\
& X_{1}<X_{0}
\end{aligned}
$$

Equation (4) shows that the utility after the event (such as a conflict or natural disaster) is lower compared to the pre-event utility, because the income is lower and the risk is higher. For relative deprivation, it is difficult to make an assumption about its sign, but it can be expected that

\footnotetext{
9 "Bogus refugees" are defined as individuals who intend to migrate voluntarily and, in the case of a conflict, are using the current political situation in a country in order to claim their right to refugee status in a host country.
} 
(most) individuals are not likely to be better off once the event occurs. Hence, we assume that the change in relative deprivation cannot completely offset the combined effects of reduced income and security. This condition is required to make the difference between $U_{1}$ and $U_{0}$ always negative, regardless of the direction of change in $R D$.

As presented above (Eq.1), $R D$ is a non-linear function of the cumulative income of a reference group. In order to include $R D$ in the model and make the necessary mathematical operations, a transformation of Equation (1) from definite integral to linear form is required. Following Stark and Taylor (1991), this is done by a first-order Taylor-series transformation of Equation (1) around $Y_{0 .}{ }^{10}$ The Taylor-series transformation approximates a small change in $R D$ by the product of a small change in the individual's income and the first-order derivative of its $R D$ with respect to income. After this transformation, $Y_{1}$ can be replaced by $Y_{0}+w_{1}$ and $R D_{1}$ by $R D_{0}+$ $R D^{\prime}{ }^{\prime} w_{1}$, where $w_{1}=Y_{1}-Y_{0}$ is the individual's income loss from conflict and $R D^{\prime}$ is the derivative of $R D$ with respect to $Y$ (hence, $R D^{\prime}{ }^{\prime} W_{1}$ is the change in relative deprivation caused by the change in income at Stage 1). Also, $X_{1}$ can be now expressed as $X_{0}+r_{1}$, where $r_{1}$ is the decrease in security (increase in risk) an individual faces as a result of conflict. The income loss from conflict $\left(w_{1}\right)$, when Runciman's original explanation of relative deprivation is applied, is actually the relative deprivation of individuals based on their comparison of current and pre-conflict well-being. The larger the loss, according to the restoration hypothesis, the more deprived individuals will be prone to migrate. When substituting these approximations into Equation (4), the individual's utility can be expressed as a function of $Y_{0}, R D_{0}, X_{0}, w_{1}$, and $r_{1}$. It is assumed here that $w_{1}<0$, or $Y_{1}$ $<Y_{0}$, meaning that the income of all individuals is negatively affected by a conflict or disaster, although to different extents, depending on whether an individual was in type $1 \mathrm{~A}$ or type $1 \mathrm{~B}$ status

\footnotetext{
${ }^{10}$ This is merely an approximation of the non-linear Lorenz curve by a linear tangent to it at the point of individual $i$ 's income. This transformation will therefore hold only in cases of small changes in Y. Unfortunately, this might affect the precision of the estimation of the impact of a large decrease in income on the migration decision.
} 
in Figure 1 (i.e. was affected by conflict only, or by both conflict and displacement). There may be some exceptions, ${ }^{11}$ but it is expected that most individuals will be worse off in terms of income after the occurrence of the conflict (whether changing from 0 to $1 \mathrm{~A}$ or from 0 to $1 \mathrm{~B}$ in Figure 1 ). Also, it may be assumed that, for the majority of people, except those at the bottom of the income distribution, relative deprivation decreases because of decline in the average income, which may have a positive impact on the migration of highly skilled individuals, because their "positive" relative deprivation (i.e. their relative advantage) actually decreases $\left(\Delta R D_{1}<0\right)$. Finally, it is assumed that $r_{1}<1$ (reduction in security), or $X_{1}<X_{0}$, which means that security decreases (risk increases) with occurrence of a conflict or a disaster.

$$
\begin{aligned}
\Delta U_{1} & =U_{1}\left(Y_{0}+w_{1}, R D_{0}+R D_{0}^{\prime} w_{1}, X_{0}+r_{1}\right)-U_{0}\left(Y_{0}, R D_{0}, X_{0}\right) \\
& =\phi\left(Y_{0}, R D_{0}, X_{0}, w_{1}, r_{1}\right)
\end{aligned}
$$

Equation (5) shows that a change in utility from $U_{0}$ to $U_{1}$, as a consequence of a conflict or natural disaster (which, for some individuals, includes forced displacement), is a function of initial income $\left(Y_{0}\right)$, initial relative deprivation $\left(R D_{0}\right)$ and intial risk $\left(X_{0}\right)$ as well as of decrease in absolute income $\left(w_{1}\right)$ and decrease in security (increase in risk) $\left(r_{1}\right)$ during the event. After the individual experiences such a decrease in utility, the situation in terms of the difference between the utility of staying and the utility of migrating abroad changes, so that the original positive difference between the utility of staying compared to the utility of migrating $\left(U_{0}>U_{2}\right)$ can turn negative $\left(U_{1}<U_{2}\right)$. So, some individuals, in the second stage of the process of displacement described in Figure 1, decide to migrate. In the second stage, therefore, the net utility gain from migration is:

$$
\Delta U_{2}=U_{2}-U_{1}=U_{2}\left(Y_{2}, R D_{2}, X_{2}\right)-U_{1}\left(Y_{1}, R D_{1}, X_{1}\right)
$$

\footnotetext{
${ }^{11}$ For example, smugglers who exploit difficulties caused by a conflict and get rich by reselling goods at extremely high margins.
} 


$$
\begin{aligned}
& Y_{2}>Y_{1} \text {, or } \\
& R D_{2}<R D_{1} \text {, or } \\
& X_{2}>X_{1}
\end{aligned}
$$

The first part of Equation (6) is similar to Equation (4). However, Equation (4) represents the change in the individual's utility in the first stage of forced migration, whereas Equation (6) is for Stage 2 of migration. It is also assumed here that the individuals are rational economic agents, so at least one of the inequalities from the second part of Equation (6) should hold in order to observe migration by an individual. This means that an individual migrates if they expect to increase their utility by migrating, which will increase at least one of the elements of their utility, either absolute income, or relative advantage, or security (risk reduction).

Next, we transform Equation (6) into Equation (7) by applying the procedure used in the transformation of Equation (4) into (5), i.e. approximating Stage 2 variables by the Stage 1 variables plus changes in these variables resulting from migration (i.e. the change from Stage 1 to Stage 2):

$$
\Delta U_{2}=U_{2}\left(Y_{1}+w_{2}, R D_{1}+R D_{1}^{\prime} w_{2}, X_{1}+r_{2}\right)-U_{1}\left(Y_{1}, R D_{1}, X_{1}\right)
$$

Equation (5) represents the change in utility as a result of displacement and/or conflict (Stage 1) and Equation (7) represents the change in utility as a result of conflict-induced migration (Stage 2). However, as Runciman (1966: 10) stated, in his original explanation of relative deprivation, individuals not only compare their current situation with the reference group, but also with their own situation in some previous time period. Applied in the context of forced migration as a twostage process, this means that the change in utility of an individual as a result of migration, presented in Equation (7), depends not only on the absolute income and relative deprivation in 
Stage 1, before migration, but also on these values in Stage 0, before displacement and conflict, as hypothesized above through the "restoration" hypothesis. Consequently, we incorporate this hypothesis into the final model of migration as a result of displacement by substituting the Stage 1 values for $U_{1}()$ from Equation (5) into Equation (7) and introducing $U_{0}($ ) (also from Eq.5). Whereas Equation (5) represents change in utility as a result of conflict (Stage 0 to Stage 1 - i.e. both Groups $1 \mathrm{~A}$ and $1 \mathrm{~B}$ in Figure 1), and Equation (7) represents change in utility as a result of migration (Stage 1 to Stage 2 - i.e. both Groups $2 \mathrm{~A}$ and 2B), Equation (8) represents the entire two-stage process (TSP) of moving from Stage 0 to Stage $2-\mathrm{U}_{\text {TSP }}()$.

$$
\begin{aligned}
& \Delta U_{T S P}=U_{2}\left(Y_{0}+w_{1}+w_{2}, R D_{0}+R D_{0}^{\prime} w_{1}+R D_{1}^{\prime} w_{2}, X_{0}+r_{1}+r_{2}\right)-U_{1}\left(Y_{0}+w_{1}, R D_{0}+R D_{0}^{\prime} w_{1}, X_{0}+r_{1}\right. \\
& )-U_{0}\left(Y_{0}, R D_{0}, X_{0}\right)
\end{aligned}
$$

The final two-stage model of forced migration is presented by Equation (9). The model shows that the conflict-induced migration decision depends on the difference between the current level of utility (Stage 1) and the utility of migration (Stage 2), but is conditional on the pre-conflict level of utility (Stage 0 ).

$$
\Delta U_{2}=\theta\left(Y_{0}, R D_{0}, R D_{1}, R D_{0}{ }^{\prime} w_{1}, R D_{1}{ }^{\prime} w_{2}, X_{0}, w_{1}, w_{2}, r_{1}, r_{2}\right)
$$

Equation (9) reveals that the migration decision in the conflict setting, when incorporating the effect of relative deprivation and relative loss of utility during the conflict (and, for some individuals, also displacement) depends on: the initial income level $\left(Y_{0}\right)$; initial relative deprivation $\left(R D_{0}\right)$ and relative deprivation after displacement and/or conflict $\left(R D_{1}\right)$; change in income due to displacement and/or conflict $\left(w_{1}\right)$ and income gain from migration $\left(w_{2}\right)$; difference in relative deprivation not only between the situation before and after migration $\left(R D_{1}{ }^{\prime} w_{2}\right)$, but also with 
regard to the change caused by conflict and, for some, displacement $\left(R D_{0}{ }^{\prime} w_{1}\right)$, as well as risk increase as a consequence of conflict $\left(r_{1}\right)$ and security increase (risk decrease) as a result of migration $\left(r_{2}\right)$. Variable $Y_{0}$ is the standard income variable of migration models. The relative deprivation hypothesis is captured by $R D_{0}$ and $R D_{1}$, while the restoration hypothesis is presented in the model by variables $w_{1}, w_{2}, R D^{\prime} w_{1}$ and $R D^{\prime} w_{2}$ (i.e. income changes in each stage, together with changes in relative deprivation caused by those changes in income). Finally, the risk factors influencing conflict-induced migration are represented by variables $X_{0}, r_{1}$ and $r_{2}$ (initial risk and changes in risk in each stage).

The theoretical model presented above has three novel features. First, compared to the model of Stark and Taylor (1991), this model incorporates the risk factor. Therefore, it may be considered as a more appropriate model to be used in the context of forced migration, instead of models developed for voluntary migration. Second, forced migration in this model is presented as a two-stage process of migration. Third, this model along with the risk factor also incorporates two hypotheses that are considered important factors influencing the forced migration decision process, namely (i) relative deprivation from Stark and Taylor (1991) and (ii) a new "restoration" hypothesis proposed in this paper. Individuals compare their relative position to not only the reference group in a single period of time, but also to their own position at a previous point in time. Thus, the migration decision is influenced both by pre-conflict income and relative deprivation ( $Y_{0}$ and $\left.R D_{0}\right)$ and by their change $\left(w_{1}\right.$ and $\left.R D^{\prime} w_{1}\right)$ during the conflict. Not only does our model have novel features, but it also has direct implications for the previously noted issue of the skill composition of migrants. Compared to the Stark and Taylor (1991) model, our model is extended by introducing the role of the change in income $\left(w_{1}\right)$ and relative deprivation $\left(R D^{\prime} w_{1}\right)$ as a result of conflict as additional determinants of migration decisions. Referring to Equation (9), on the assumption that the income and associated well-being as well as the relative position of 
individuals with high skill levels are more adversely impacted by conflict than are the income and associated well-being of individuals with lower skill levels, the model predicts that individuals with high skills will be more likely to migrate than those with low skills.

The model can be tested empirically both at the individual and at the national level. At the individual level, both the individual and the community's incomes give information about the absolute and relative position of an individual within a society as well as information about whether the forcible displacement of an individual during conflict or disaster can be used as a proxy measure of a change in her or his relative deprivation. At the national level, GDP and its difference before and after events measure absolute income and its change, respectively. Measures of inequality, such as the Gini or the Theil coefficient, can be used as a proxy for relative deprivation. Change in these coefficients measures change in relative deprivation. The extent of mass displacement can be captured by the number of internally displaced individuals within a country. The level of risk to all individuals can be measured by information on the total number of deaths during a conflict or a disaster.

\section{Conclusions}

This paper presents a new model motivated by specific features of forced migration during a conflict - first identified by qualitative analysis of mass displacement experiences in Bosnia and Herzegovina (Oruc 2015) - which do not feature in existing migration models. Our model incorporates the relative deprivation hypothesis and a new "restoration" hypothesis, in order to better explain forced migration described here as a two-stage process, which starts with conflict and, in some cases, forced displacement in the first stage and continues with emigration in the second stage. A particular feature of our model is that it predicts self-selection of highly skilled individuals into international migration as a result of conflict, since the "restoration" hypothesis assumes that individuals with a higher income (where education is an important determinant of 
income) before conflict are more under pressure to restore their previous income through emigration. Although our model was inspired mainly by the specific case of forced migration from $\mathrm{BiH}$, we argue that it may apply more generally to forced migration, perhaps irrespective of specific contexts and causes. Of course, this claim must be tested. To this end, we propose further research to investigate the sphere of validity of our model: first, in the specific context of $\mathrm{BiH}$ (on the "home ground" of our model, so to speak); and then in a variety of other contexts.

Other types of mass forced migration share displacement with conflict-induced migration as the key characteristic of the migration process, such as migration induced by natural disasters or large development projects. Hence, the model used in this paper to analyse conflict-induced migration can serve to motivate and guide further modelling to better match the characteristics of migration induced by natural disasters and large development projects. ${ }^{12}$ In this way, specific models better tailored to different types of migration can be developed. These models, by capturing the specific characteristics of each type of migration, should have better predictive power compared to simple applications of voluntary migration models to all types of forced migration. Then, separate empirical studies of the impact of such migration on the stock of human capital for each type of migration could be conducted. This way, empirical evidence would be generated for better estimation of the overall costs of events such as conflicts, natural disasters or large development projects.

Given that our model predicts selection of the more highly educated into (external) migration, suggesting that conflict exacerbates "brain drain", the model suggests two important policy implications. First, because conflicts cause considerable depletion of human capital, one suggestion to policy makers might be that a post-conflict recovery strategy should treat education investments aimed at recovering human capital with as much priority as investments in

\footnotetext{
${ }^{12}$ Natural disaster-induced migration is expected to become a particularly important type of migration, due to climate change.
} 
infrastructure destroyed during the conflict. In addition to education investments relying on local resources, countries should also investigate policies designed to incentivise return of forced migrants, hence enhancing "brain gain".

Finally, this paper also contributes to the literature on the impact of conflicts on the economic development of a country affected by them, by offering a model able to account for depletion of human capital as a result of displacement, in addition to other costs of conflict. Accordingly, this article may motivate further research on the costs of conflicts as well as future assessments of total reparations to be paid by countries starting a war. 


\section{References}

Beine, M., F. Docquier and H. Rapoport 2006. "Measuring International Skilled Migration: New Estimates Controlling for Age of Entry", World Bank International Migration and Development Program, Working paper.

Berry, R. A. and R. Soligo 1969 "Some welfare effects of international migration", Journal of political economy, No. 77, pp. 778-794.

Borjas, George J. 1987. "Self-Selection and the Earnings of Immigrants", American Economic Review, September 1987, pp. 531-553.

Chiswick, B. R. 2000. "Are Immigrants Favourably Self-Selected? An Economic Analysis", IZA Discussion Paper No. 31.

Czaika, M and K. Kis-Katos 2007. Civil Conflict and Displacement: Village-Level Determinants of Forced Migration in Aceh (Manuscript, University of Freiburg).

Davenport, CA, Moore, WH and Poe, SC 2003. "Sometimes You Just Have to Leave: Domestic Threats and Forced Migration, 1964-1989," International Interactions, 29, pp. 27-55.

Docquier, F. an A. Marfouk 2006. "International migration by educational attainment, 1990-2000", in C. Ozden and M. Schiff (eds.) International migration, "brain drain" and remittances (Palgrave Macmillan, New York).

Dostie, B. and P. T. Leger 2006. "Self-Selection in Migration and Returns to Skills", CIRPEE Working Paper 06-12.

Gratz, D 2007. Elitocide in Bosnia and Herzegovina 1992 - 1995, PhD Thesis (Institute for Peace Research and Security Policy, University of Hamburg).

Grubel, H. G. and A. D. Scott 1966. "The International Flow of Human Capital”, American Economic Review, No. 56, pp. $268-274$. 
Ibanez, A. M. and C. E. Velez 2003. "Forced Displacement in Colombia: Causality and Welfare Losses", World Bank Research Paper, June 2003.

Kirchhoff, S. and A. M. Ibanez 2001. "Displacement Due to Violence in Colombia: Determinants and Consequences at the Household Level", ZEF Discussion Paper No. 41.

Lucas, R.E. 1988. "On the Mechanics of Economic Development," Journal of Monetary Economics, 22, 3-42.

Mandic, D. 2017. "Anatomy of a Refugee Wave: Forced Migration on the Balkan Route as Two Processes", https://www.europenowjournal.org/2017/01/04/anatomy-of-a-refugee-wave-forced-migration-onthe-balkan-route-as-two-processes/, accessed on 1 February 2019.

Melander, E. and M. Oberg 2004. "Forced Migration: The Effects of the Magnitude and Scope of Fighting", Uppsala Peace Research Paper, No. 8.

Moore, W.H. and S.M. Shellman 2006. "Refugee or Internally Displaced Person? To Where Should One Flee?", Comparative Political Studies, 39 (5), pp. 599-622.

Oruc, N. 2009. "Self-Selection in Conflict-Induced Migration: Micro Evidence from Bosnia", wiiw Balkan Observatory Working paper, No. 78.

Oruc, N. 2015. "Urban IDPs and Poverty: Analysis of the Effect of Mass Forced Displacement on Urban Poverty in Bosnia and Herzegovina", Croatian Economic Survey : Vol. 17 : No. 1 : June 2015 : pp. 4770.

Pedersen, PJ, Pytlikova. M and N. Smith 2004. "Selection or Network Effects? Migration Flows into 27 OECD Countries, 1990-2000", IZA Discussion Paper, No. 1104.

Roy, A. D. 1951. "Some Thoughts on the Distribution of Earnings", Oxford Economic Papers 3, pp. 135-146.

Runciman, W.G. 1966. Relative deprivation and social justice: a study of attitudes to social inequality in twentieth-century England, (University of California Press, Berkeley).

Schon, J. 2018. "Motivation and opportunity for conflict-induced migration: An analysis of Syrian migration timing", Journal of Peace Research, 56(1), pp. 12-27. 
Sjaastad, L.A. 1962. "The Costs and Returns of Human Migration", The Journal of Political Economy, 70 (5), Part 2, pp. 80-93.

Stark, O and Yitzhaki, S 1988. "Labour Migration as a Response to Relative Deprivation", Journal of Population Economics, 1 (1), pp. 57-70.

Stark, O. and J. E. Taylor 1991. "Relative deprivation and Migration: Theory, Evidence and Policy Implications", World Bank Working Paper WPS 656.

Stouffer, S.A., E.A. Suchman, L.C. DeVinney, S.A. Starr and R.M. Williams 1949. The American Soldier: Adjustment to Army Life. Vol. 1., (Princeton University Press, Princeton N.J.).

Van Hear, N. 1998. New Diasporas: The mass exodus, dispersal and regrouping of migrant communities, (UCL Press, London). 